\title{
The Analgesic Efficacy of Low Dose Dexamethasone Added to Bupivacaine in Ilioinguinal and Iliohypogastric Nerves Block in Patients Undergoing Inguinal Hernia Surgery Under Spinal Anesthesia
}

\author{
Hamid Kayalha $^{1,2}(\mathbb{D})$, Somayeh Ahmadi Gooraji2 ${ }^{2}$, Hossein Parsa ${ }^{3}(\mathbb{D})$, Marzieh Beigom Khezri*1,2
}

1. Rajaee Clinical Research Development Unit, Qazvin University of Medical Sciences, Qazvin, Iran

2. Metabolic Disease Research Center, Qazvin University of Medical Sciences, Qazvin, Iran

3. Dept. of Biostatistics, Guilan University of Medical Sciences, Guilan, Iran

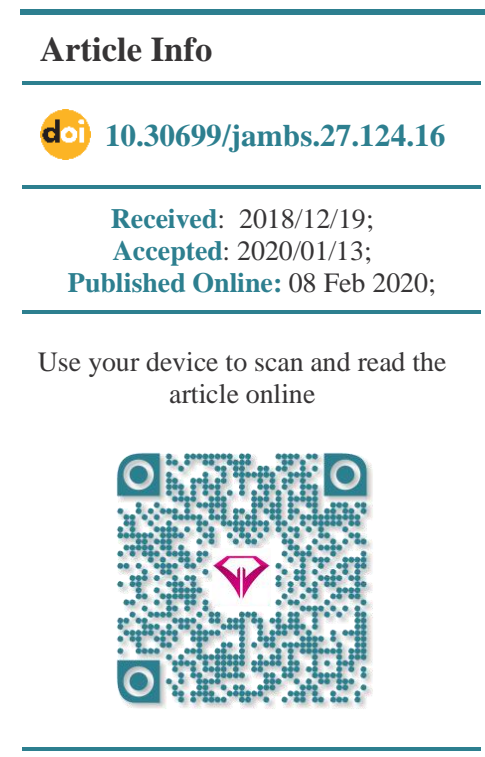

Corresponding Information: Dr. Marzieh Beigom Khezri, Rajaee Clinical Research Development Unit, Qazvin University of Medical Sciences, Qazvin, Iran.

E-mail: mkhezri@qums.ac.ir

\begin{abstract}
Background \& Objective: Dexamethasone has been emerged as an adjuvant to local anesthetics to provide optimal analgesia. We have evaluated the postoperative analgesic efficacy of adding a low dose dexamethasone to bupivacaine in ilioinguinal (II) and iliohypogastric (IH) blocks in patients undergoing inguinal herniorraphy under spinal anesthesia.
\end{abstract}

Materials \& Methods: 50 patients in the range of 20-80 years of age who had underwent elective surgery for the purpose of inguinal hernia repair under spinal anesthesia were recruited in a prospective, double-blinded, and randomized manner. At the end of the surgery, the patients received an II and IH block through the direct injection of drugs around nerves. Meanwhile, the control group received bupivacaine $0.5 \%$ ( $2 \mathrm{cc}$ ) plus normal saline $1 \mathrm{cc}$ (group C), and the dexamethasone group received bupivacaine $0.5 \%(2 \mathrm{cc})$ plus $4 \mathrm{mg}(1 \mathrm{cc})$ dexamethasone (group D). The pain intensity was measured using the visual analogue scale (VAS) scale at 1, 2, 4, 12, and 24 hours after surgery.

Results: The mean time of analgesic duration in group $\mathrm{C}(3.6 \pm 3.8 \mathrm{hr})$ was greater than group D $(1.6 \pm 1.14 \mathrm{hr})$. This difference was statistically significant $(P=0.043)$. The pain intensity 2 hours after surgery in group $\mathrm{D}$ was higher than in group $\mathrm{C}$ (median with IQR: $3 \pm 4$ vs. $2 \pm 2 ; P=0.007$ ). The difference in the total analgesic consumption in group D $(51.1 \pm 32.4 \mathrm{mg})$ versus group C $(26.4 \pm 33.8 \mathrm{mg})$ was significant $(P=0.018)$.

Conclusion: The addition of $4 \mathrm{mg}$ dexamethasone to bupivacaine in an II and IH block at the end of surgery in patients undergoing inguinal herniorraphy under spinal anesthesia failed to prolong the time to the first analgesic request. It provides only a minor analgesic effect 12 hours following the surgery.

Keywords: Dexamethasone, Inguinal herrniorraphy, Ilioinguinal nerve, Iliohypogastric nerve, Pain

Copyright $\odot$ 2019, This is an original open-access article distributed under the terms of the Creative Commons Attribution-noncommercial 4.0 International License which permits copy and redistribution of the material just in noncommercial usages with proper citation.

\section{Introduction}

The management of postoperative pain causes better surgical outcomes and fewer cognitive changes following surgery. It reduces the risk of chronic pain and improves the quality of life. Using common analgesic agents such as opioids after inguinal hernia repair surgery causes delayed intestinal function and increases side effects such as nausea and vomiting (1$3)$, resulting in increased hospital costs (4).

Postoperative pain management after abdominal surgical procedure (inguinal herniorrhaphy) is usually based on conventional agents consisting of maximal doses of paracetamol non-steroidal anti-inflammatory drugs, and oral or intravenous opioid. However, this is associated with such side effects as nausea, drowsiness and hemodynamic disturbance, and reduced lung capacity. Ilioinguinal (II) and iliohypogastric (IH) nerve blocks could provide satisfactory analgesia after inguinal hernia. Many drugs have been added to local anesthetics to offer ideal analgesia with lesser side effects such as opioids, epinephrine, ketamine, midazolam, clonidine, dexamethasone, and magnesium (5).

II and IH nerve blocks are not used as the sole anesthesia approaches for surgery because they are unable to provide visceral insensitivity (6). The II/IH nerve block has been suggested to decrease the opioid analgesic requirements and adverse effects after inguinal herniotomy (7). 
Perineural dexamethasone has been shown to have analgesic effects. It is suggested that the analgesic effect of dexamethasone is related to decreased inflammation and the blocking of the nociceptive $\mathrm{C}$ nervous fibers via inhibiting the ectopic nerve discharges. This enhances the time of the nerve block (8). Furthermore, dexamethasone constricts the blood vessels and reduces the absorption of local anesthesia drugs (9). Many studies have reported that there are no problems associated with the use of perineural dexamethasone in a peripheral nerve block (9-15).

In a meta-analysis by De Oliveira which included the overall results of three studies $(13,14,16)$ examining the effect of perineural dexamethasone on late pain $(24 \mathrm{~h})$, no favorable effect for dexamethasone was reported compared to the control group. They also stated that only one study assessed the effect of perineural dexamethasone on early pain $(<4 \mathrm{~h})$ in patients receiving an interscalene brachial plexus block with levobupivacaine; the results of the study proposed that there is a minor effect of perineural dexamethasone compared to the control group $(\mathbf{1 1}, 16)$. However, the authors declared that the heterogeneity of the studies was high and it could not describe the type of regional block or the local anesthetic used. Although several studies have shown that perineural dexamethasone prolongs the analgesic duration $(11,13,14,16)$ of biracial plexus, the literature on the efficacy of perineural dexamethasone in other peripheral nerve blocks, such as those in the distribution of the lumbar or II and IH blocks, is limited $(\mathbf{1 7 , 1 8 )}$. Further research is needed in this area.

We hypothesized that adding a low dose of dexamethasone to bupivacaine in II and IH nerve blocks might offer a better pain killer after inguinal herniorraphy surgery under spinal anesthesia compared to the common anesthetic agents with lower side effects. In order to test our hypothesis, we scheduled a randomized double-blind placebocontrolled (RDBPC) study to assess the postoperative analgesic effects of a perineural low dose of dexamethasone added to bupivacaine in II and IH nerve blocks at the end of inguinal hernia repair surgery.

\section{Materials and Methods}

The study was approved by the ethics committee of the Qazvin University of Medical Sciences, Qazvin, Iran. This was a randomized double blind clinical trial performed on 50 patients aged between 20-80 years with ASA class I \& II (American society of anesthesiologists) who underwent one-sided inguinal hernia repair surgery at the Rajaee and Velayat hospitals, both of which are affiliated to the Qazvin University of Medical Sciences, Qazvin, Iran. The time period of the study was from January 2016 to January 2017 (IRCT registration number: IRCT2017012425676N6). All patients were completely informed about the study protocols and provided a written informed consent. The exclusion criteria were addiction, palliative care, a surgery time of more than $1.5 \mathrm{~h}$, the inadequate analgesic efficacy of the spinal anesthesia during surgery, and the patients considered for hernia repair with a surgical mesh. Out of 50 patients primarily included in the study, 6 patients were excluded from the study groups for study protocol reasons. The guidelines provided by the Consolidated Standards of Reporting Trials (CONSORT) for recording randomized controlled clinical trials (19) were charted (Figure 1).

All patients received an intravenous preload of lactated Ringer's solution at $5-7 \mathrm{ml} / \mathrm{kg}$ before the subarachnoid block. Afterward, via an aseptic technique, a 25-gauge Quincke needle was introduced intrathecally via a midline method at the L4-5 interspace by the same anesthetist, who was uninformed of the patient assignment when the patient was in the sitting position. After the dural puncture, the anesthetic solution (3 $\mathrm{ml}$ bupivacaine $0.5 \%$ ) was injected.

Using a computer-generated randomization schedule, 50 patients aligned with the ASA physical grade I or II, who had underwent inguinal hernia repair surgery by spinal anesthesia were randomized to have II and IH blocks with the direct injection of medicine around the nerves tissues conducted by the surgeon. At the end of the surgery, all patients had an established II and IH block with the direct injection of medicine around the nerve tissues. Patients in the control group received bupivacaine $0.5 \%(2 \mathrm{cc})$ plus normal saline $1 \mathrm{cc}$ (group C) and the patients in the intervention group received bupivacaine $0.5 \%$ (2 cc) plus dexamethasone $1 \mathrm{cc}(4 \mathrm{mg}$ ) (group D). Blinding was attained through the use of the same volume of the study drugs $(3 \mathrm{~mL})$. The syringes used were categorized as either A and B according to their contents. The identically coded syringes, prepared by an external individual, were arbitrarily given to the surgeon who was uninformed of the identity of the syringes. The primary outcomes of this study were to assess the time taken to first pain feeling and the total analgesic required in the first 24 hours postoperative. The patients were preoperatively taught to use the verbal analog scale (VAS) from 0 to 10 (0: no pain, and 10: maximum imaginable pain) for the pain assessment. If the VAS exceeded 4 and the patient requested a supplement analgesic, then diclofenac $\mathrm{Na}$ sup. $100 \mathrm{mg}$ was administered every 8 hours to terminate the postoperative pain as needed. If the time course after the use of diclofenac $\mathrm{Na}$ was lesser than 8 hours and the patient requested another supplement analgesic, then pethidine $50 \mathrm{mg}$ IV was injected. The study data was analyzed by a statistician who was not elaborated on the purpose of the study.

To estimate the sample size, the data from a prior similar study was assessed (20). Our primary outcome was the duration of analgesia. The data (mean \pm SD) from the previous study (20) which referred to the 
Table 1. Demographic information of patients $(n=44)$

\begin{tabular}{ccccc} 
Variable & Category & D $(\mathbf{n = 2 3})$ & C (n=21) & P-value \\
Sex, n (\%) & Male & $21(91.3)$ & $20(95.2)$ & $0.535^{\mathrm{a}}$ \\
& Female & $2(8.7)$ & $1(4.8)$ & $0.907^{\mathrm{b}}$ \\
\hline
\end{tabular}

$\mathrm{D}=$ bupivacaine \&dexamethasone group as case group, $\mathrm{C}=$ bupivacaine $\&$ normal saline as control group.

${ }^{\mathrm{a}}$ Analysis done based on Chi-square test. ${ }^{\mathrm{b}}$ Analysis done based on independent two samples T-test.

Table 2. Comparison the main outcomes between two groups $(n=44)$

\begin{tabular}{cccc} 
Variable & $\begin{array}{c}\mathbf{D}(\mathbf{n}=\mathbf{2 3}) \\
\text { Mean } \pm \text { SD }\end{array}$ & $\begin{array}{c}\text { C }(\mathbf{n}=\mathbf{2 1}) \\
\text { Mean } \pm \text { SD }\end{array}$ & P-value $^{\text {a }}$ \\
Pethidine consumption & $51.1 \pm 32.4$ & $26.4 \pm 21.8$ & $0.018^{*}$ \\
Diclofenac Na consumption & $91.3 \pm 44.8$ & $114.3 \pm 57.3$ & 0.303 \\
Pain onset time & $1.6 \pm 1.14$ & $3.6 \pm 3.2$ & $0.043^{*}$ \\
\hline
\end{tabular}

${ }^{\mathrm{a}}$ Independent samples T-test. * Is significant at level of $0.05 . \mathrm{D}=$ dexamethasone group, $\mathrm{C}=$ control group.

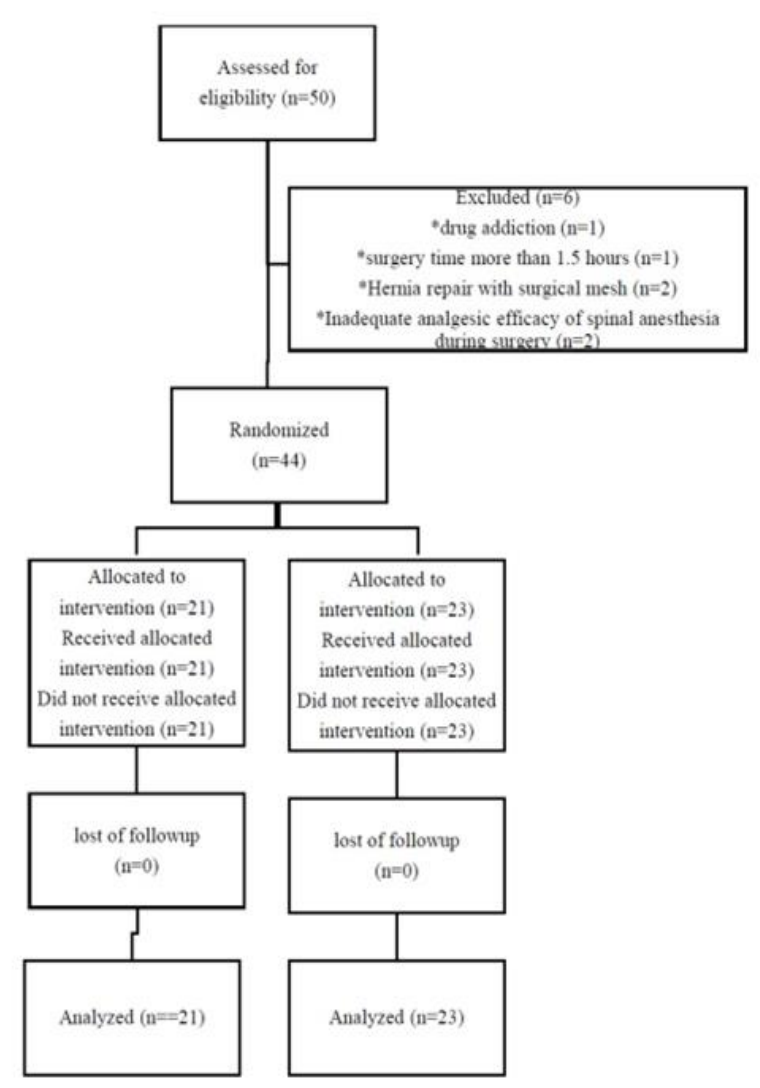

Figure 1. Consort flow diagram

duration of analgesia was entered into the Open Epi program software. The sample size analysis conducted suggests that a total of 38 patients are mandatory to distinguish if there is a significant difference in the mean duration of analgesia between the groups using 


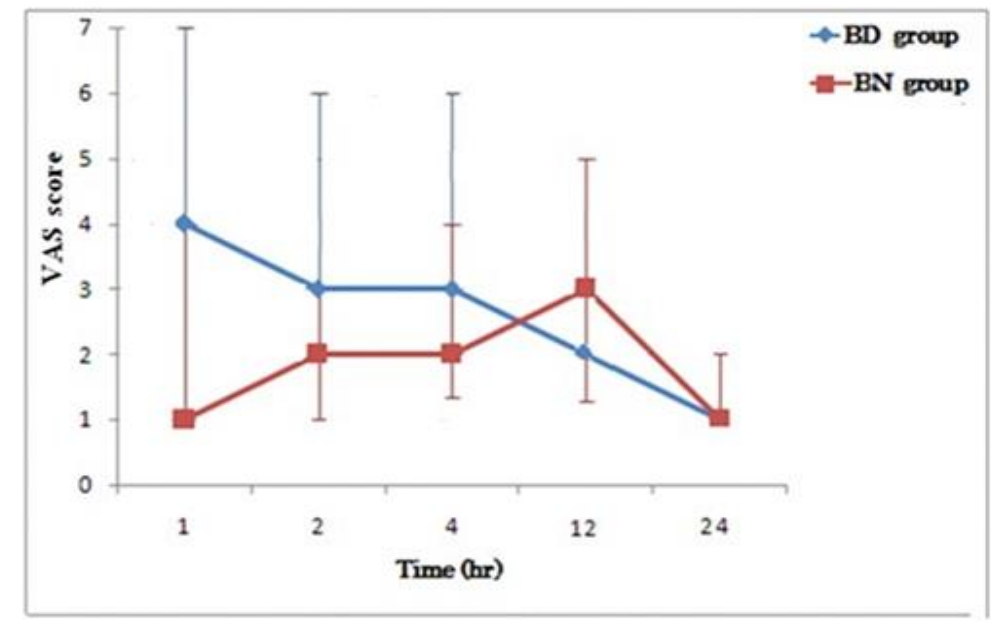

Figure 2. Data are representd based on Median and Interquartile rang(IQR).

the Mann-Whitney $U$ test, with a power of 0.9 and $\alpha$ equal to 0.05 . We employed a total of 50 patients to allow for dropouts and protocol limitations. The data was analyzed using SPSS 15 (SPSS Inc., Chicago, IL, USA). Continuous variables were checked for normal distribution using the Kolmogorov-Smirnov test. The parametric data were shown in the form of mean and standard deviation (SD) and analyzed using the independent sample t-test. The non-parametric data was revealed as utilizing the median and interquartile ranges, and this was analyzed using the MannWhitney U test and Chi-square test. A P-value less than 0.05 was considered to be statistically significant.

\section{Results}

A total of 50 patients were first registered in this study, out of whom 6 patients were excluded due to the following reasons: drug addiction (1 patient), a surgery time of more than 1.5 hours (1 patient), patients undergoing hernia repair with surgical mesh ( 2 patients), and the inadequate analgesic efficacy of spinal anesthesia during surgery ( 2 patients). Finally, 44 patients were involved and randomly allocated to their treatment groups (Figure 1).

As shown in Table 1, there were no significant differences between the two groups concerning the demographic characteristics.

Table 2 shows that the mean time of analgesic duration in group $\mathrm{C}(3.6 \pm 3.8 \mathrm{~h})$ was greater than that in group $\mathrm{D}(1.6 \pm 1.14 \mathrm{~h})$. This difference was statistically significant $(P=0.043)$. Meanwhile, the difference in total analgesic consumption in group D $(51.1 \pm 32.4 \mathrm{mg})$ vs. group C $(26.4 \pm 33.8 \mathrm{mg})$ was significant $(P=0.018)$.

Figure 2 presents the comparison of trends in pain intensity in each time and by groups. As observed, although the pain intensity at $12(P=0.083)$ and 24
$(P=0.161)$ hours following surgical operation was lower in group D, compared to group C, the difference was not statistically significant.

\section{Discussion}

Based on the results of the present study, we concluded that the addition of $4 \mathrm{mg}$ dexamethasone to bupivacaine in the II and IH blocks at the end of surgery in patients undergoing inguinal herniorraphy under spinal anesthesia could not prolong the time to the first analgesic request. It only provided minor analgesic effects 12 hours after surgery. Contrary to our results, most of the previous studies reported a significant analgesic effect for dexamethasone plus bupivacaine or ropivacaine (9,17,21-27). Nevertheless, partially consistent with present results and in a meta-analysis by De Oliveira et al. (11), it was described that the results of three studies $(13,14,16)$ showed that the effect of perineural dexamethasone on late pain $(24 \mathrm{~h})$ did not have a favorable effect compared to the control group.

The discrepancy in the results of the current study with those of the previous studies may be due to different routes, dosages, and also the time of dexamethasone administration used. For example, in a study by Vieira et al. (14), it was described that the addition of $8 \mathrm{mg}$ dexamethasone to a bupivacaineepinephrine-clonidine interscalene block prolonged the sensory block and reduced opioid use. They declared that minor doses of dexamethasone $(4-5 \mathrm{mg}$ ) were not as effective as major doses $(8-10 \mathrm{mg})$ at decreasing analgesic consumption 24 and 48 hours after surgery (14). In another study performed by Parrington et al. (13), for 46 adult patients undergoing elective surgery under the supraclavicular brachial plexus, a longer median time for analgesia after surgery was reported in the group that received 
mepivacaine $1.5 \%$ (30 $\mathrm{mL})$ plus dexamethasone $8 \mathrm{mg}$ compared to the group that received mepivacaine $1.5 \%(30 \mathrm{~mL})$ plus normal saline $2 \mathrm{ml}$. However, the onset of the sensory and motor block did not lessen in comparison with normal saline (13). In our previous study we concluded that adding $8 \mathrm{mg}$ dexamethasone to $40 \mathrm{~mL}$ lidocaine meaningfully elongated the duration of analgesia compared with the fentanyl/lidocaine mixture or lidocaine alone using the axillary block in patients suffering post-forearm fracture surgery (5). In a study by Cummings et al. (9), it was also revealed that adding $8 \mathrm{mg}$ dexamethasone elongated the analgesia from the interscalene blocks using ropivacaine or bupivacaine, compared to ropivacaine. Castillo et al. (28) reported that in rats, dexamethasone alone or when combined with aqueous bupivacaine has no effect on the analgesic effects of a sciatic nerve block. However, when combined with bupivacaine microspheres, the effects were meaningful. This result is partly consistent with the finding of the present study; however, it should be noted that microsphere technology provides a sustained and prolonged release of the drug in contrast to the aqueous solutions used in our study.

Ammar et al. (17) reported that adding $8 \mathrm{mg}$ dexamethasone to bupivacaine in the transversus abdominis plane block (TAPB), before the start of the surgery and after the induction of general anesthesia, prolonged the duration of the analgesia. In a study by Fouad et al. (23), it was revealed that the preemptive addition of $8 \mathrm{mg}$ dexamethasone to bupivacaine in patients receiving a TAPB for inguinal hernia repair under general anesthesia resulted in a longer time for the first opioid requirement.

We performed the II and IH block at the end of the surgery, but in the above-mentioned studies, dexamethasone was given before starting the surgery. It is known that the biological half-life of dexamethasone in plasma is about 190 minutes (29). Nevertheless, the exact onset of the perineural dexamethasone action is not well established; but the onset of the biological action of dexamethasone is reported to be between 1-2 hours following administration $(30,31)$. Therefore, it seems that the drug should ideally be administered prior to surgery in order to achieve the maximum benefit. The authors of the present study assumed that the time of blocking and injection of drugs may be important in relation to the analgesic efficacy of dexamethasone. Dexamethasone has long-acting effects and it could work as an optimal agent when used as preemptive analgesia (32).

The important finding of the present study that should be noted is the occurrence of the early onset of pain in patients who received a low dose of dexamethasone added to bupivacaine in the II and IH blocks at the end of surgery. This result was somehow comparable with the finding of the literature review by Knezevic et al. (33). They described that perineural adjuvant dexamethasone prolonged the onset of the sensory and motor block. In the present study, in patients who received dexamethasone, the onset of pain appeared earlier than expected. In other words, the onset of bupivacaine effect in the II block was delayed. The vasoconstriction effect of dexamethasone may be a possible explanation for delaying the onset of the bupivacaine block. That is to say, dexamethasone constricts vessels and reduces the absorption of the local anesthesia drugs (9). Another possibility worth mentioning as an explanation for the delayed onset of the bupivacaine block is that the effect of dexamethasone in this study was more pronounced because we added $1 \mathrm{~mL}$ dexamethasone to $2 \mathrm{ml}$ bupivacaine $0.5 \%$. In most of the aforementioned studies, 1-2 $\mathrm{ml}$ dexamethasone was added to $20 \mathrm{ml}$ bupivacaine $0.5 \%$.

We chose the administration of $4 \mathrm{mg}$ dexamethasone because some previous studies revealed that minor doses of dexamethasone $(4-5 \mathrm{mg})$ were as effective as major doses $(8-10 \mathrm{mg})(\mathbf{1 6}, \mathbf{3 0})$. In a study by Khafagy et al. (22), it was also reported that the addition of $4 \mathrm{mg}$ dexamethasone to epidural bupivacaine had almost the same analgesic effect as bupivacaine-fentanyl with opioid-sparing and antiemetic properties.

Our study had some limitations. We did not assess the dose-response of dexamethasone. Also, measuring pain intensity is challenging, especially for patients with severe and chronic pain. The VAS is limited by ceiling effects, in that often the patients were unable to quantify their worsening pain. Moreover, this assessment is clearly subjective and the medical staff were unable to monitor the patients' pain over extensive periods of time $(34,35)$. Additional research is necessary to assess either different dosages of the short-acting steroids at the end of surgery on postoperative pain or the use of one of the alkalization agents such as bicarbonate $\mathrm{Na}$ in addition to steroids to accelerate the analgesic effect of the drugs with an evaluation of the patients' pain via a digital VAS scale to offer a suitable way for the medical staff to monitor the patients' pain over substantial periods of time. We suggest the use of preemptive perineural high dose dexamethasone in addition to II and IH blocks for postoperative pain relief.

\section{Conclusion}

The addition of $4 \mathrm{mg}$ dexamethasone to bupivacaine in II and IH blocks at the end of surgery in patients undergoing inguinal herniorraphy under spinal anesthesia could not prolong the time to the first analgesic request. It could provide only a minor analgesic effect 12 hours following surgery. 


\section{Acknowledgement}

Authors of this paper are thankful for the valuable cooperation of the staff of Clinical Research Development units of Velayat and Rajaee hospitals.

\section{Conflict of Interest}

Authors declared no conflict of interests.

\section{References}

1. Fink WA Jr. The pathophysiology of acute pain. Emerg Med Clin North Am .2005; 23(2): 277-84. [DOI:10.1016/j.emc.2004.12.001]

2. Callesen $\mathrm{T}$, Kehlet $\mathrm{H}$. Post herniorrhaphy pain. Anesthesiology. 1997; 87(5): 1219-30. [DOI:10.1097/00000542-199711000-00027]

3. Pavlin DJ, Rapp SE, Polissar NL, Malmgren JA, Koerschgen M, Keyes H. Factors affecting discharge time in adult outpatients. Anesth Analg. 1998; 87(4) 816-26. [DOI:10.1097/00000539-199810000-00014]

4. Junger A, Klasen J, Benson $\mathrm{M}$, et al. Factors determining length of stay of surgical day-case patients. Eur J Anaesthesiol. 2001;18(5): 314-21. [DOI:10.1097/00003643-200105000-00006]

5. Yaghoobi S, Seddighi M, Yazdi Z, Ghafouri R, Khezri MB. Comparison of postoperative analgesic effect of dexamethasone and fentanyl added to lidocaine through axillary block in forearm fracture. Pain Res Treat. 2013;2013: 761583. [DOI: $10.1155 / 2013 / 761583$ ]

6. Nienhuijs SW, Rosman C, Strobbe LJ, Wolff A, Bleichrodt RP. An overview of the features influencing pain after inguinal herniarepair. Int $\mathrm{J}$ Surg .2008; 6(4):351-6 [DOI:10.1016/j.ijsu.2008.02.005]

7. Miller RD. Millers anesthesia. Canada, Elsevier saunders;2015: 2976-1736

8. Bani-Hashem N, Hassan-Nasab B, Pour EA, Maleh PA, Nabavi A, Jabbari A. Addition of intrathecal dexamethasone to bupivacaine for spinal anesthesia in orthopedic surgery. Saudi J Anaesth. 2011;5(4): 382-86. [DOI: $10.4103 / 1658-354 X .87267]$

9. Cummings KC , Napierkowski DE, Parra-Sanchez I, et al. Effect of dexamethasone on the duration of interscalene nerve blocks with ropivacaine or bupivacaine. Br J Anaesthesia .2011; 107(3):1-88. [DOI: 10.1093/bja/aer159]

10. Desmet M, Braems H, Reynvoet M, et al. IV and perineural dexamethasone are equivalent in increasing the analgesic duration of a single-shot interscalene block with ropivacaine for shoulder surgery: a prospective, randomized, placebocontrolled study. Br J Anaesth .2013: 111(3): 445-52. [DOI:10.1093/bja/aet109]

11. De Oliveira GS Jr, Castro Alves LJ, Nader A, Kendall MC, Rahangdale R, McCarthy RJ. Perineural dexamethasone to improve postoperative analgesia with peripheral nerve blocks:a metaanalysis of randomized controlled trials. Pain Res Treat. $2014 ; 2014$ : 179029. [DOI:10.1155/2014/179029]

12. Movafegh A, Razazian M, Hajimaohamadi F, Meysamie A. Dexamethasone added to lidocaine prolongs axillary brachial plexus blockade. Anesth Analg. $\quad 2006 ; \quad 102(1)$ : 263- 7 [DOI:10.1213/01.ane.0000189055.06729.0a]

13. Parrington SJ, O'Donnell D, Chan VW, et al. Dexamethasone added to mepivacaine prolongs the duration of analgesia after supraclavicularbrachial plexus blockade. Reg Anesth Pain Med .2010; 35(5):422-6. [DOI:10.1097/AAP.0b013e3181e85eb9]

14. Vieira PA, Pulai I, Tsao GC, Manikantan P, Keller B, Connelly NR. Dexamethasone with bupivacaine increases duration of analgesia in ultrasound-guided interscalene brachial plexus blockade. Eur J Anaesthesiol. 2010; 27(3):285. [DOI:10.1097/EJA.0b013e3283350c38]

15. Albrecht E, Kern C, Kirkham KR. A systematic review and metaanalysis of perineural dexamethason for peripheral nerve blocks. Anaesthesia .2015;70(1):71-83. [DOI:10.1111/anae.12823]

16. Kim YJ, Lee GY, Kim DY, Kim CH, Baik HJ, Heo S. Dexamathasone added to levobupivacaine improves postoperative analgesia in ultrasound guided interscalene brachial plexus blockade for arthroscopic shoulder surgery. Korean J Anesthesiol. 2012;62(2):130-4. [DOI:10.4097/kjae.2012.62.2.130]

17. Ammar AS, Mahmoud KM. Effect of adding dexamethasone to bupivacaine on transversusabdominis plane block for abdominal hysterectomy: A prospective randomized controlled trial. Saudi J Anaesthesia. 2012; 6(3):229-233. [DOI:10.4103/1658-354X.101213]

18. Rahangdale R, Kendall MC, McCarthy RJ, et al. The effects of perineural versus intravenous dexamethasone on sciatic nerve blockade outcomes: a randomized, double-blind, placebo-controlled study. Anesth Analg. 2014;118(5):1113-9. [DOI:10.1213/ANE.0000000000000137]

19. Moher D, Schulz KF, Altman DG. The CONSORT statement: revised recommendations for improving the quality of reports of parallel group randomised trial. Lancet 2001; 357(9263):1191-4. [DOI:10.1016/S0140-6736(00)04337-3]

20. Ribeiro KS, Ollapally A, Misauith J. Dexamethason as an adjuvant to bupivacaine in superaclavicular brachial plexus block in pediatrics for postoperative analgesia. J Clin Diagn Res .2016; 10(12): UC01UC04. [DOI:10.7860/JCDR/2016/22089.8957]

21. Bang YS, Park C, Lee SY, Kim M, Lee T. Comparison between monitored anesthesia care with remifentanil under ilioinguinal hypogasteric nerve block and spinal anesthesia for herniorrhaphy. Korean J Anesthesiol. 2013; 64(5): 414-9. [DOI:10.4097/kjae.2013.64.5.414]

22. Khafagy HF, Refaat AI, El-Sabae HH, Youssif MA. Efficacy of epiduraldexamethasone versus fentanyl 
on postoperative analgesia. J Anesth. 2010; 24(4):531-36. [DOI:10.1007/s00540-010-0949-7]

23. Fouad HA, Sabry Ahmed AM, Mohammed Osman YM, Taha Abouelmagd GM. Eefficacy of pereemptive dexamethasone to bupivacaine in ultrasound guidedtransversusabdominus plain block for postoperative analgesia after inguinalherniorraphy. Am J Res Commun .2016; 4(5): $27-42$

24. Almajali Z, Batarseh E, Daameh S, Qabha A, Haddadin M. Comparison of postoperative pain relief impact between caudal bupivacaine alone and caudal bupivacaine-dexamethasone mixture administration for pediatric local tube urethroplasty. J R Nav Med Serv .2014; 21(4): 19-24. [DOI:10.12816/0008061]

25. Girgis K. The effect of adding dexamethasone to bupivacaine on the duration of postoperative analgesia after caudal anesthesia in children. AinShams J Anesthesio. 2014; 7(3):381-87. [DOI: 10.4103/1687-7934.139573]

26. Mahmoud MS, Abd Al Alim AA, Hefni AF. Dexamethasone bupivacaine versus bupivacaine for peribulbar block in posterior segment eyesurgery. Egypt J Anaesthesia .2013; 29(4): 407-11 [DOI:10.1016/i.egja.2013.07.003]

27. Ma'somi A, Abshirini $H$, HekmatShoar $M$. Comparison of local anesthetic effect of bupivacaine versus bupivacaine plus dexamethasone in nasal surgery. Iran J Otorhinolaryngol. 2013; 25(70):7-10.

28. Castillo J, Curley J, Hotz J, et al. Glucocorticoids prolong rat sciatic nerve blockade in vivo from bupivacaine microspheres. Anesthesiology. 1996; 85(5):1157-66. [DOI:10.1097/00000542-199611000$\underline{00025]}$

29. Sapolsky RM, Romero LM, Munch AU. Pharmacokinetics and pharmacodynamics of dexamethasone sodium-m-sulfobenzoate (DS) after intravenous and intramuscular administration: a comparison with dexamethasone phosphate (DP). J ClinPharmacol .2001; 41(4):425-34. [DOI:10.1177/00912700122010285]

30. Sapolsky RM, Romero LM, Munch AU. How do glucocorticoids influence stress responses? Integrating permissive, suppressive, stimulatory and preparative actions. Endocr Rev. 2000;21:55-89.33. [DOI:10.1210/er.21.1.55]

31. Jaleel F, Jaleel R, Ahsan MI. Efficacy and timing of single dose dexamethasone as prophylactic antiemetic in major surgeries. J Surg Pakistan (international). 2009;14 (2): 48-52

32. Knezevic NN, Anantamongkol U, Candido KD. Effect of perioperative perineural injection of dexamethasone and bupivacaine on a rat spared nerve injury model. Korean J Pain. 2010; 23(3):16671. [DOI:10.3344/kjp.2010.23.3.166]

33. Knezevic NN, Anantamongkol U, Candido KD. Perineural dexamethasone added to local anesthesia for brachial plexus block improves pain but delays block onset and motor blockade recovery. Pain Physician . 2015; 18(1):1-14.

34. González-Fernández M1, Ghosh N, Ellison T, McLeod JC, Pelletier CA, Williams K. Moving beyond the limitations of the visual analog scale for measuring pain: novel use of the general labeled magnitude scale in a clinical setting. Am J Phys Med Rehabil. 2014;93(1):75-81. [DOI:10.1097/PHM.0b013e31829e76f7]

35. Delgado DA1, Lambert BS1, Boutris N1. Validation of digital visual analog scale pain scoring with a traditional paper-based visual analog scale in adults. J Am Acad Orthop Surg Glob Res Rev. 2018 :23;2(3):e088. [DOI:10.5435/JAAOSGlobal-D-17$\underline{00088]}$

\section{How to Cite This Article:}

Kayalha H, Ahmadi Gooraji S, Parsa H, Khezri M B. The Analgesic Efficacy of Low Dose Dexamethasone Added to Bupivacaine in Ilioinguinal and Iliohypogastric Nerves Block in Patients Undergoing Inguinal Hernia Surgery under Spinal Anesthesia. J Adv Med Biomed Res. 2019; 27 (124): 16-22

\section{Download citation:

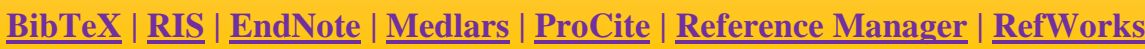

\section{Send citation to:}

(3) Mendelev 2 Zotero RefWorks $\underline{\text { RefWorks }}$ 